\title{
Exposure Lot Number
}

National Cancer Institute

\section{Source}

National Cancer Institute. Exposure Lot Number. NCI Thesaurus. Code C83099.

The numerical identifier of the medication exposure lot. 